\title{
$\mathrm{RC} \& \mathrm{C}$
}

REVISTA DE CONTABILIDADE E CONTROLADORIA

\author{
AVALIAÇÃO DA INFLUÊNCIA DE TEXTOS \\ NARRATIVOS DE FATOS RELEVANTES NO PREÇO DAS \\ AÇÕES DE EMPRESAS BRASILEIRAS
}

\section{EVALUATION OF PRESS-RELEASES NARRATIVE TEXTS INFLUENCE IN PRICE OF BRAZILIAN COMPANIES' SHARES}

Recebido em 05.07.2010| Aceito em 02.08.2010 | 2a versão aceita em 25.08.2010|

Nota: este artigo foi aceito pelos Editores Romualdo Douglas Colauto e Ademir Clemente e passou por um avaliação double blind review

\section{CÉSAR AUGUSTO TIBÚRCIO SILVA}

Doutor | Professor do Programa Multiinstitucional e Inter-Regional de PósGraduação em Ciências Contábeis | UnB/UFPB/UFRN | Campus Darcy Ribeiro | Ed. FAD - sala B102 Asa Norte | 70910-900 | Brasília, DF | E-mail: cesartiburcio@unb.br |

\section{ELIANE DA SILVA FELIPE}

Mestre | Programa Multiinstitucional e Inter-Regional de Pós-Graduação em Ciências Contábeis | UnB/UFPB/UFRN | Parque Estação Biológica, W3 Norte s.n | Ed. Embrapa Sede, sala 315 | 70770-901 | Brasília, DF | E-mail: eliane.felipe@embrapa.br I

\section{RESUMO}

As decisões da administração das companhias abertas, capazes de interferir nas escolhas de acionistas, investidores, credores e demais interessados em seu desempenho, são consideradas fatos relevantes e devem ser divulgadas à medida que ocorrem, não se sujeitando a uma periodicidade específica. Como tais comunicações costumam apresentar-se sob a forma de narrativa, sem um formato pré-estabelecido, e não sofrem auditoria, é possível questionar se a linguagem utilizada nestas divulgações é capaz de interferir no valor das ações em negociação. Para investigar esta possível influência, empregou-se a metodologia de estudo de eventos para avaliar o comportamento do preço de negociação de ações de companhias abertas na Bolsa de Valores de São Paulo durante os anos de 2006 e 2007. Fatos relevantes divulgados durante estes dois anos foram extraídos dos arquivos da BOVESPA e Comissão de Valores Mobiliários e classificados, subjetivamente, em otimistas, pessimistas ou neutros, de acordo com a 


\begin{abstract}
linguagem empregada em suas narrativas. Assim, foram investigados os comportamentos dos retornos anormais das ações referentes a 419 fatos otimistas e 79 pessimistas em períodos anteriores e posteriores às suas publicações pessimistas em períodos anteriores e posteriores às suas publicações. Observou-se uma tendência geral ao decréscimo no retorno anormal de companhias após a divulgação de fatos pessimistas, enquanto os retornos anormais ligados a fatos otimistas apresentaram variações pouco significativas. Tais observações apontam para o conservadorismo do mercado financeiro ao considerar boas e más notícias com cautela, dando maior importância aos anúncios pessimistas que aos otimistas, além de distinguir o conteúdo da linguagem nas comunicações a que é exposto.
\end{abstract}

Palavras-chave: Fatos Relevantes, Estudo de Eventos, Companhias Abertas, Retorno de Ações.

\begin{abstract}
Companies' management decisions have the ability to change the choices of shareholders, investors, creditors and others interested in its performance. This knowledge is consider relevant news and should be disclosed as it happens, but not restrained to any regular interval. The facts disclosed usually occur in the narrative form, with no pre-established format, and it's not subject to any audit inspection. This raises the issue of how the language used on these disclosures is able to affect the value of a share in the market. The approach of event study was used to conduct the study of a possible influence on the market price tendency for shares of companies listed on the Bolsa de Valores de São Paulo, during the years of 2006 and 2007. The press-releases disclosed during these years were extracted from the archives of Bovespa and Comissão de Valores Mobiliários, and classified subjectively as optimistic, pessimistic or neutral, according to the expression used in the narrative. The study investigates the behavior of the abnormal returns of shares in the period-enclosed prior and after the disclosure, on a total of 419 optimistic facts and 79 pessimistic. As a result, was observed a general tendency of decrease of the abnormal return of companies after the disclosure of pessimistic facts, while the abnormal returns linked to optimistic news showed no significant variation. Such observations show a conservative approach of the market, in considering good and bad news with caution, giving more importance to pessimistic announcements, rather than to optimistic ones. Furthermore, the user should be able to identify the communication essence of the expression when it is revealed.
\end{abstract}

Keywords: Press-Releases, Event Study, Companies, Stock Return.

\title{
1 INTRODUÇÃO
}

As decisões da administração das companhias, capazes de interferir nas escolhas de acionistas, investidores, credores e demais interessados, são consideradas fatos relevantes e devem ser divulgadas à medida que ocorrem não se sujeitando a uma periodicidade específica. Segundo Silva e Fernandes (2007), os fatos relevantes diferem dos relatórios contábeis em dois aspectos principais: a periodicidade e o enfoque. Enquanto os fatos relevantes apresentam um enfoque narrativo e podem ser veiculados a qualquer momento, os relatórios contábeis enfocam valores numéricos e devem ser publicados em 
intervalos de tempo preestabelecidos, como trimestral ou anual, por exemplo. A Lei 6.404/76, Lei das Sociedades por Ações, trata em seu artigo 157 das informações a serem prestadas pelos administradores de companhias abertas. Em seu parágrafo 4으, tal lei determina que:

os administradores da companhia aberta são obrigados a comunicar imediatamente à bolsa de valores e a divulgar pela imprensa qualquer deliberação da assembléia-geral ou dos órgãos de administração da companhia, ou fato relevante ocorrido nos seus negócios, que possa influir, de modo ponderável, na decisão dos investidores do mercado de vender ou comprar valores mobiliários emitidos pela companhia.

A ampla divulgação de informações tempestivas e fidedignas é necessária para garantir o eficiente funcionamento do mercado de capitais, evitando que pequenos grupos sejam privilegiados pelo acesso exclusivo ou antecipado a estas informações, em detrimento de seus demais competidores (RODRIGUES, 2005). Deste modo, é importante que a pública comunicação de fatos ou atos relevantes seja feita de forma a garantir a todos os elementos do mercado uma tomada de decisão consciente, baseada na interpretação individual de informações comuns.

De acordo com a Comissão de Valores Mobiliários - CVM (2008), os acionistas necessitam estar bem informados para fiscalizar a atuação dos administradores e proferir votos conscientes nas assembléias. $O$ objetivo da divulgação de fatos relevantes é a garantia de condições igualitárias na competição entre todos integrantes do mercado, não devendo ser utilizada como instrumento de manipulação ou especulação. Assim, a linguagem e a forma como os textos narrativos das comunicações são redigidos precisam ser claros, objetivos e imparciais, de modo a permitir a transmissão das informações de forma não enviesada.

Diante do exposto, este trabalho pretende responder a seguinte pergunta de pesquisa: a linguagem usada nos fatos relevantes influencia o valor das ações negociadas na bolsa de valores? Como conseqüência, o objetivo do trabalho é verificar se a linguagem empregada na redação de textos comunicativos de fatos relevantes exerce influência sobre o comportamento do mercado, impactando na precificação de ações negociadas em bolsa de valores brasileira.

\section{REFERENCIAL TEÓRICO}

Além de informações periódicas, as empresas com ações negociadas em bolsas de valores são obrigadas a divulgar informações relevantes, relacionadas às suas atividades, por meio de comunicados ao mercado, realizados a qualquer tempo, geralmente por meio de jornais de grande circulação e sob a forma de textos narrativos. Estes comunicados são conhecidos como fatos relevantes. A Instrução CVM n $\cong 358 / 2002$, que dispõe sobre a divulgação destes fatos relevantes pelas companhias abertas, os define do seguinte modo:

considera-se relevante, para os efeitos desta Instrução, qualquer decisão de acionista controlador, deliberação da 
assembléia geral ou dos órgãos de administração da companhia aberta, ou qualquer outro ato ou fato de caráter político-administrativo, técnico, negocial ou econômicofinanceiro ocorrido ou relacionado aos seus negócios que possa influir de modo ponderável:

I - na cotação dos valores mobiliários de emissão da companhia aberta ou a eles referenciados;

II - na decisão dos investidores de comprar, vender ou manter aqueles valores mobiliários;

III - na decisão dos investidores de exercer quaisquer direitos inerentes à condição de titular de valores mobiliários emitidos pela companhia ou a eles referenciados.

Com o intuito de proteger os interesses dos investidores, a Comissão de Valores Mobiliários, utilizando-se da Instrução 358 de 03 de janeiro de 2002, dispõe sobre a obrigatoriedade da comunicação de eventos que possam influir em suas decisões. A instrução cita, ainda, alguns dos casos em que a divulgação destas informações faz-se necessária e faculta ao administrador ou acionista controlador a comunicação caso estes entendam "que sua revelação porá em risco interesse legítimo da companhia".

Outra exigência é a publicação do fato relevante em jornal de grande circulação, habitualmente utilizado pela companhia, o que pode ocorrer de forma resumida, desde que expresso o sítio de divulgação de seu conteúdo integral na internet e seu conteúdo mínimo apresente o mesmo teor daquele remetido à CVM e bolsa de valores.

Apesar da discriminação, pela CVM, de alguns eventos considerados relevantes e passíveis de comunicação ao mercado, é a própria empresa que determina o que irá divulgar. Além disso, não há regulamentação que determine a periodicidade para que companhias abertas divulguem fatos relevantes. Estes devem ser comunicados tão logo ocorram os eventos que noticiam e atuam como instrumento de constante comunicação entre as empresas e seus acionistas e investidores. Tal preocupação com a ampla e imediata divulgação de fatos é uma forma de reduzir a assimetria da informação (PEREIRA, 2008).

Outra característica da demonstração em questão relaciona-se à ausência de padronização de leiaute e linguagem. Diferentemente da maioria das demonstrações contábeis obrigatórias, os fatos a serem noticiados são apresentados sob a forma narrativa, embora seja facultada a utilização conjunta de dados numéricos e outros recursos gráficos e visuais. Desta forma, a auditoria destas informações financeiras torna-se inviável, o que facilita sua utilização para viabilizar a manipulação de seus usuários.

Com tais características, estes comunicados apresentam grande divergência de estrutura e linguagem entre si, dificultando análises e interpretações por parte de seus destinatários e tornando necessário o emprego de técnicas diferentes das normalmente utilizadas na decodificação dos demais dados contábeis. Além disso, o livre emprego da linguagem possibilita que os usuários da informação sejam influenciados ou, mesmo induzidos em suas interpretações e, conseqüentemente, em suas decisões.

Segundo Verrecchia (2001), a pesquisa da evidenciação em contabilidade pode ser classificada em três categorias principais, baseadas na associação, descrição ou eficiência. Seus estudos demonstram que quando a obtenção de informações privadas é exógena, as 
relações entre evidenciação, preço de ações e volume negociado alteram-se. E sua principal conclusão é a verificação de que, na presença de custos ou incertezas, administradores preferem evidenciar informações sobre o valor da empresa a retê-las, mesmo que agentes externos sejam capazes de compreender a eventual omissão dessas informações.

Verrecchia (2001) relata, ainda, a tendência histórica de a economia incentivar, por iniciativa dos administradores, a evidenciação voluntária. Ponto forte que, segundo o autor, sobrepuja pontos fracos, como a preferência das empresas por modelos e premissas, que maximizem o valor corrente de mercado e os resultados dos relatórios, o fato de na literatura os resultados serem altamente sensíveis às premissas e a ineficiência de estratégias discricionárias quando empregadas a empresas que optam por não evidenciar. Verifica-se, também, a existência de grande potencial ao estabelecer ligações entre a evidenciação e a redução da assimetria da informação. No entanto, estabelecer tal relação em estudos empíricos não é tarefa fácil, pois essa ligação, normalmente, não é evidente, embora as pesquisas não a ignorem.

Para que a relação entre a divulgação de informações financeiras e a reação do mercado de capitais seja estabelecida, é necessário que as informações sejam corretamente disponibilizadas, de forma que seu receptor tenha acesso fiel e integral ao fato retratado. Nesse processo, o código, ou seja, a linguagem utilizada para transportar o conteúdo da mensagem deve ser de domínio de ambos, tanto do emissor quanto do receptor. Assim, uma das pretensões da comunicação é que a mensagem recebida pelo leitor seja interpretada de acordo com as intenções do remetente. Mas, em comunicações narrativas, elementos como conteúdo, formato, organização e estilo podem ajudar ou atrapalhar a compreensão do leitor (COURTIS, 1998).

Dias Filho e Nakagawa (2001) discutem a extensão do nível de compreensão dos usuários das evidenciações contábeis. Além da utilização de termos técnicos, os autores atentam para a atribuição de novos significados às palavras de uso comum, transformando-as em termos técnicos contábeis, nem sempre compreensíveis aos usuários. Dias Filho (2000) sugere que características médias dos usuários sejam identificadas, assim como os elementos mais significativos no processo de comunicação contábil, uma vez que valores e objetivos costumam ser compartilhados por grupos com interesses comuns.

Agrega-se a isso, a possibilidade de as informações sofrerem distorções de origem semântica, desde o momento em que são produzidas. Tais distorções podem ser explicadas pelos diferenciados níveis de interpretação dos eventos e compreensão dos princípios, normas e práticas contábeis por parte daqueles que elaboram as informações.

A partir das conclusões de estudos sobre a linguagem utilizada em divulgações narrativas e reações do mercado acionário diante da divulgação de informações, é possível questionar a influência da divulgação de fatos relevantes sobre o preço de negociação das ações de uma companhia. 


\section{PROCEDIMENTOS METODOLÓGICOS}

O estudo sobre a reação do mercado financeiro à divulgação de informações contábeis teve sua origem nos anos de 1960 em dois trabalhos fundamentais para a pesquisa contábil: 'An Empirical Evaluation of Accounting Numbers', de Ray Ball e Philip Brown, e 'Market Prices, Financial Ratios, and the Prediction of Failure', de Willian Beaver, ambos no ano de 1968. Posteriormente, vários trabalhos foram desenvolvidos com o intuito de relacionar variáveis contábeis aos preços das ações, tanto em mercados internacionais quanto no brasileiro.

No Brasil, vários autores dedicaram-se a pesquisar a influência das informações contábeis sobre o preço das ações, ou seja, a relacionar a reação do mercado à divulgação das informações. Percebe-se que a metodologia mais utilizada por eles é o Estudo de Evento, que, segundo Lamounier e Nogueira (2007, p.1): “[...] é a metodologia que procura mensurar o impacto de uma informação pública, divulgada em um dado momento, no comportamento dos preços dos títulos." Ainda, segundo estes autores, o estudo de eventos "visa, a partir da hipótese de que os mercados sejam eficientes, mensurar o impacto da divulgação de uma dada informação no valor da empresa, mais especificamente no comportamento dinâmico dos preços e dos retornos dessa firma nos mercados financeiros."

Para o desenvolvimento do estudo, foram coletados os fatos relevantes referentes aos anos de 2006 e 2007 e disponibilizados no sítio da Bolsa de Valores de São Paulo Bovespa - na internet, http://siteempresas.bovespa.com.br. Os dados foram baixados e nomeados um por um para os estudos de legibilidade de Silva e Fernandes (2007) e são acessíveis, também, no sítio da CVM, pela opção Informações Periódicas e Eventuais - IPE.

Desta forma foram obtidos 2.350 arquivos, 962 com fatos divulgados em 2006 e 1.388 referentes a 2007, sendo que um dos arquivos, de fato relevante divulgado em 2007, apresentou erro, não abriu e, por isso, foi desconsiderado.

Os arquivos obtidos no site na Bovespa foram lidos individualmente e classificados em otimista, pessimista ou neutro, de acordo com a linguagem empregada. Ressalta-se que classificação subjetiva foi atribuída à linguagem utilizada nas narrativas e não a seu conteúdo. Assim, fatos relevantes, apresentando apenas tabelas e gráficos, sem maiores considerações, tiveram sua linguagem classificada como neutra. Por outro lado, informações ressaltando oportunidades de mercado e possíveis ganhos foram considerados otimistas, enquanto aqueles que enfatizam prejuízos, perda de mercado ou redução de atividades foram classificados como pessimistas.

Os critérios para esta classificação foram estabelecidos pelos pesquisadores, considerando sua percepção sobre a linguagem dos textos, na tentativa de estabelecer uma aproximação à possível influência sofrida pelos usuários externos em geral. A síntese da classificação dos dados coletados resultou na Tabela 1. 
Tabela 1: Classificação de linguagem.

\begin{tabular}{c|ccc}
\hline CLASSIFICAÇÃO & $\mathbf{2 0 0 6}$ & $\mathbf{2 0 0 7}$ & TOTAL \\
\hline Otimistas & 310 & 418 & $\mathbf{7 2 8}$ \\
\hline Pessimistas & 75 & 49 & 124 \\
\hline Neutros & 577 & 920 & 1.497 \\
\hline TOTAL & 962 & 1.387 & 2.349 \\
\hline
\end{tabular}

Na Tabela 1 ressalta-se o emprego de linguagem considerada neutra, ou seja, atendo-se à comunicação de fatos, sem enfatizar aspectos positivos ou negativos. Percebe-se, também, a redução do emprego de linguagem pessimista de 2006 para 2007, mesmo tendo crescido o número de publicações de um ano a outro.

Para prosseguir com a pesquisa, foi necessário respeitar a janela de eventos de 20 dias anteriores e 20 dias posteriores à divulgação de cada fato relevante. Ou seja, para que os efeitos de um fato relevante pudessem ser analisados sem a interferência de outra publicação em período próximo, foram excluídos fatos relevantes de mesma empresa publicados em intervalo inferior a 40 dias. Deste modo, foram excluídos da amostra 354 fatos relevantes, 137 referentes a 2006 e 217 a 2007. A composição da amostra passou a ser representada na Tabela 2.

Tabela 2: Classificação e Janela de Eventos

\begin{tabular}{l|ccc}
\hline CLASSIFICAÇÃO & $\mathbf{2 0 0 6}$ & $\mathbf{2 0 0 7}$ & TOTAL \\
\hline Otimistas & 200 & 219 & 419 \\
\hline Pessimistas & 48 & 31 & 79 \\
\hline TOTAL & 248 & 250 & 498 \\
\hline
\end{tabular}

Conforme exposto, a amostra de estudo passou a contar com 498 fatos relevantes, sendo 419 de linguagem otimista e 79 pessimistas. As empresas com fatos relevantes, selecionados na amostra, tiveram as cotações de fechamento de suas ações negociadas na Bovespa coletadas por meio da base de dados Economática.

Primeiramente, optou-se por considerar os preços de negociação das ações ordinárias (ON). Nos casos em que estas não apresentavam liquidez suficiente, ou seja, o mínimo de $80 \%$ de cotações, para o período analisado, foram considerados os preços das ações preferenciais (PN). Houve, ainda, casos em que nenhum tipo de ação, ON ou PN, apresentou liquidez de $80 \%$, estabelecida como mínima necessária para a análise, no intervalo temporal definido como janela de evento. Nesses casos, o evento a ser estudado foi excluído.

Para os dados faltantes, ou seja, ações que embora apresentem $80 \%$ das cotações para o período não possuam negociação em algum(s) dia(s) do intervalo de análise, foi utilizado o método de substituição. Assim, se o dado faltante referia-se à data anterior à divulgação do fato relevante, o dado foi substituído pelo dado referente ao dia imediatamente anterior. Nos casos em que não havia cotação para a ação na data da publicação do fato ou data posterior a essa, foi considerada a cotação do dia imediatamente posterior a este, conforme apresenta-se na Tabela 3. 
Tabela 3: Fatos Classificados e Cotações de Ações Correspondentes

\begin{tabular}{|c|c|c|c|c|}
\hline CLASSIFICAÇÃO & COTAÇÕES & 2006 & 2007 & TOTAL \\
\hline \multirow{2}{*}{ Otimistas } & Suficientes & 121 & 153 & 274 \\
\hline & Insuficientes & 79 & 66 & 145 \\
\hline \multirow{2}{*}{ Pessimistas } & Suficientes & 15 & 16 & 31 \\
\hline & Insuficientes & 33 & 15 & 48 \\
\hline TOTAL & & 248 & 250 & 498 \\
\hline
\end{tabular}

A Tabela 3 demonstra as ações com cotações suficientes para a análise e sua correspondência com fatos relevantes considerados otimistas ou pessimistas. Desta forma, foi analisado um total de 305 fatos relevantes, bem como, o impacto de sua divulgação no preço de negociação das ações de suas empresas divulgadoras. Os fatos referentes a empresas com cotações insuficientes foram excluídos da análise.

Para estabelecer critérios de comparação e estimar o retorno esperado das ações, foi utilizado o Índice Bovespa (Ibovespa). O índice representa o valor atual, em moeda corrente, de uma aplicação hipotética, em carteira fictícia de ações, criada em 1968. Considera-se, ainda, que tal aplicação não sofreu qualquer investimento adicional, em que os retornos anormais das ações são agregados através do tempo e entre títulos, possibilitando inferências globais mediante a análise do comportamento desta variável.

Para avaliar o impacto causado pela divulgação dos fatos relevantes sobre o preço das ações de suas empresas, empregou-se o método utilizado por Mackinlay (1997) em que os retornos anormais das ações são agregados através do tempo e entre títulos, possibilitando inferências globais mediante a análise do comportamento desta variável.

Para avaliar o impacto do evento, é necessário calcular o retorno anormal, que pode ser determinado pelo retorno obtido menos o retorno normal da empresa durante a janela de evento (MACKINLAY, 1997). Desta forma, o retorno normal, ou retorno esperado, representa o retorno que a empresa teria na ausência do evento e o retorno anormal o impacto deste evento. $O$ cálculo do retorno anormal da ação é representado pela equação 3.1.

Onde:

$$
R A_{i, t}=R_{i, t}-R E_{i, t}
$$

$R A_{i, t}=$ Retorno Anormal da ação i no período t.

$R_{i, z}=$ Retorno obtido da ação i no período t.

$R E_{i, t}=$ Retorno Esperado da ação i no período t.

Para calcular o retorno das ações, dois métodos de capitalização poderiam ser adotados, o de capitalização discreta e o de capitalização contínua (BROOKS, 2005). A seguir estão representadas, de acordo com Pereira (2006), as equações referentes à capitalização discreta e à contínua, respectivamente: 


$$
\begin{gathered}
R_{i, t}=\frac{P_{i, t}-P_{i, t-1}}{F_{i, t}} \\
R_{i, t}=\ln \left(\frac{F_{i, t}}{P_{i t-1}}\right)=\ln P_{i, t}-\ln P_{i, t-1}
\end{gathered}
$$

Onde:

$R_{i, t}=$ Retorno da ação i no período t.

$P_{i, \pm}=$ Preço da ação i no período t.

$P_{i, t-1}=$ Preço da ação i no período $\mathrm{t}-1$.

Para cálculo do retorno esperado, foi obtido, para cada evento, o valor do intercepto e da inclinação da reta que expressa a relação entre o retorno da ação e o retorno do mercado. Como proxy do retorno do mercado, utilizou-se a variação do Ibovespa, para idêntico período da variação do retorno da ação, ou seja, sem defasagem. É importante destacar que os valores do intercepto e da inclinação foram obtidos usando dados anteriores ao evento, no caso, entre - 21 e -14 dias antes do evento. Assumiu-se, neste caso, a existência de uma relação linear simples entre as duas variáveis. Não foi realizado nenhum teste específico sobre a qualidade dos dados obtidos para as duas variáveis da regressão (intercepto e inclinação) e acredita-se que a ausência do teste não afetou o resultado obtido. Com os valores do intercepto e inclinação estimados, foi calculado o retorno esperado através da seguinte expressão:

$$
\begin{aligned}
& R_{p}^{t}=a+b R_{m}^{t} \\
& R_{p}^{t}=\text { retorno da ação no tempo " } t " \\
& R_{m}^{t}=\text { retorno do mercado em " } t "
\end{aligned}
$$

A diferença entre o retorno esperado e o retorno efetivo da ação é denominada de retorno anormal. Para cada período de tempo (dia), foi calculada esta diferença, conforme Fórmula 3.1 apresentada anteriormente.

É oportuno registrar que o retorno esperado não foi calculado por intermédio do coeficiente beta por este não apresentar uma representação uniforme nos diferentes meios que os divulgam no Brasil. Os retornos anormais individuais das ações podem ser agregados utilizando-se a equação (3.4), baseada nos estudos de Mackinlay (1997), a seguir:

$$
\overline{R A}_{\tau}=\frac{1}{N} \sum_{i=1}^{N} R A_{i \tau}
$$

Onde:

$\overline{R A}_{\tau}=$ Retorno anormal médio das ações no período $\pi$.

$\tau=T_{1}+1_{1, \ldots, T_{2}}$

$N=$ Eventos 
Utilizando-se da equação (3.4), é possível agregar o retorno anormal de diferentes títulos e, seguindo o mesmo raciocínio, é possível agregar, através do tempo, os retornos anormais médios obtidos, como demonstrados na equação (3.5), a seguir:

$$
R A A_{\left(\tau_{1}, r_{2}\right)}=\sum_{\tau}^{\tau_{\tau}} \tau_{\tau_{2}} \overline{R A}_{\tau}
$$

Onde:

$R A A=$ Retorno anormal médio acumulado das ações nos períodos $\tau_{1}$ e $\tau_{2}$.

$\overline{R A}_{\tau}=$ Retorno anormal médio das ações no período $\tau$, equação (3.4).

\section{ANÁLISE DOS RESULTADOS}

A partir dos critérios e parâmetros definidos no capítulo anterior, os estudos conduziram ao retorno anormal acumulado das ações das empresas sob análise no período delimitado pelas janelas de eventos, definidas a partir da data de divulgação de fatos relevantes.

Figura 1: Retorno Anormal Acumulado - Fatos Otimistas 2006

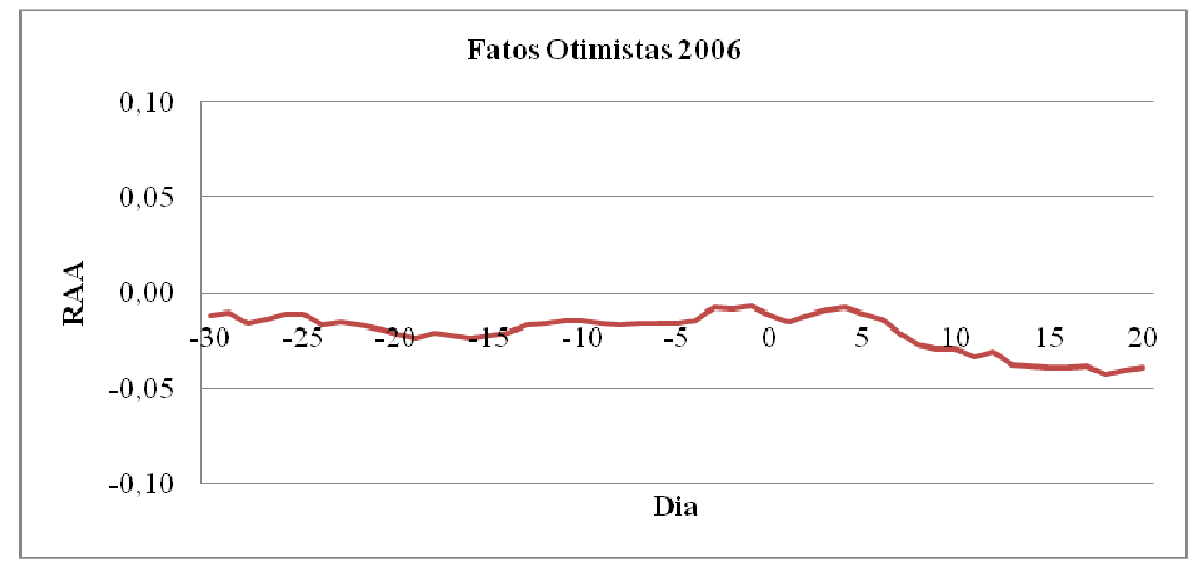

Nota: A data de publicação do fato relevante é representada pelo dia 0.

Na Figura 1 demonstra-se que no ano de 2006 as ações de empresas, que divulgaram fatos relevantes com linguagem classificada como otimista, obtiveram retorno anormal médio acumulado com variações pouco significativas, tanto antes como depois da publicação das informações, que corresponde ao dia 0 . A diferença entre o maior e o menor valor do retorno anormal médio acumulado no período é da ordem de 0,03597.

A parca variação do RAA das ações não fornece indícios suficientes para que seja estabelecida relação entre a utilização da linguagem otimista e a reação do mercado.Uma das explicações possíveis para tal comportamento seria a precaução dos usuários da informação, bem como sua habilidade em extrair o conteúdo das publicações, sem deixar que a linguagem otimista influencie suas decisões. 
A utilização de linguagem de conotação pessimista em fatos relevantes teve sua influência sobre o retorno anormal de ações representada na Figura 2.

Figura 2: Retorno Anormal Acumulado - Fatos Pessimistas 2006

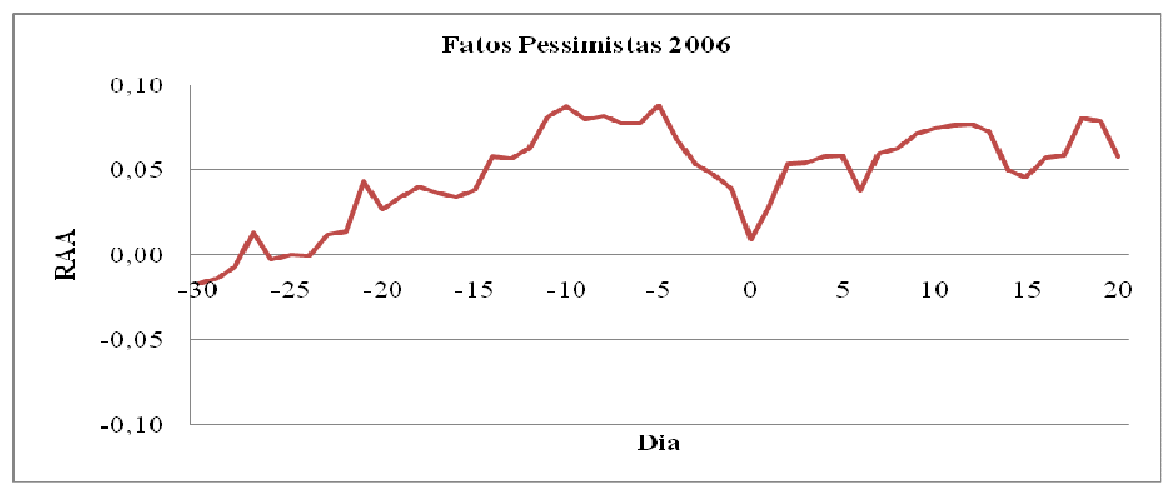

Nota: A data de publicação do fato relevante é representada pelo dia 0.

Durante o ano de 2006, o RAA das ações apresentou decréscimo a partir do quarto dia anterior à publicação dos fatos considerados pessimistas. A queda no retorno anormal médio persistiu até o dia da divulgação do fato relevante e este voltou a elevar-se nos dias seqüentes. Observe que o valor do RAA começa a decrescer no dia -4 e só volta a apresentar elevação no dia 1 . O retorno anormal médio acumulado passa de 0,08806 , no dia -5, para 0,00966, no dia 0, divulgação do fato relevante.

Tal constatação demonstra a reação do mercado à utilização de linguagem pessimista. No entanto, o breve período de decréscimo do retorno anormal leva a crer que a notícia tenha sido antecipada, ou seja, houve vazamento de informação antes da publicação oficial do fato. Assim, o mercado antecipou sua reação em alguns dias, mas não reagiu longamente ao comunicado.

Observa-se que os usuários da informação souberam de certa forma, extrair o conteúdo do comunicado sem deixar-se influenciar completamente pelas palavras da narrativa. 0 RAA das ações de empresas com fatos relevantes publicados durante o ano de 2007 está expresso nas Figuras 3 e 4 . Na Figura 3 apresenta-se o comportamento do retorno anormal médio acumulado de ações, durante o período definido pela janela de eventos, das empresas em estudo que tiveram seus fatos relevantes considerados de linguagem otimista. 
Figura 3: Retorno Anormal Acumulado - Fatos Otimistas 2007

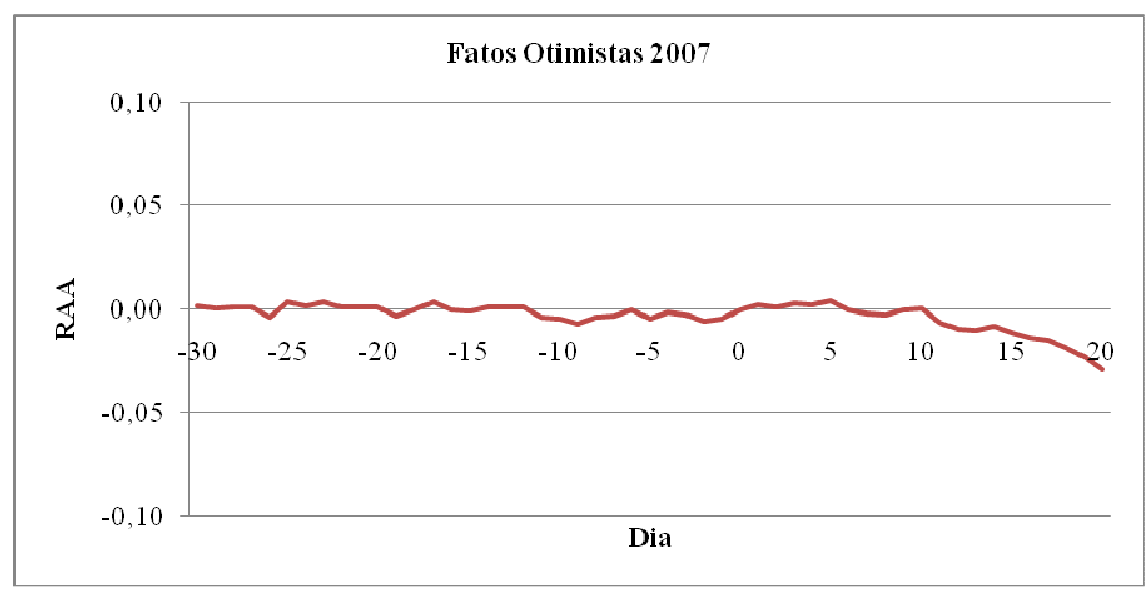

Nota: A data de publicação do fato relevante é representada pelo dia 0.

Durante o ano de 2007, o retorno anormal médio auferido pelas empresas sob análise sofreu variações pouco significativas no intervalo de 20 dias anteriores e 20 dias posteriores à divulgação das informações com narrativas otimistas. A variação do RAA do período teve 0,03304 como sua maior amplitude entre o 50 e 20으 dias do estudo.

Da mesma maneira como ocorreu com os dados referentes ao ano de 2006 , a variação do RAA não foi suficiente para comprovar a influência da linguagem otimista das narrativas sobre o comportamento de acionistas e investidores. O RAA das ações de empresas com fatos relevantes considerados de linguagem negativa em 2007 é representado na Figura 4.

Figura 4: Retorno Anormal Acumulado - Fatos Pessimistas 2007

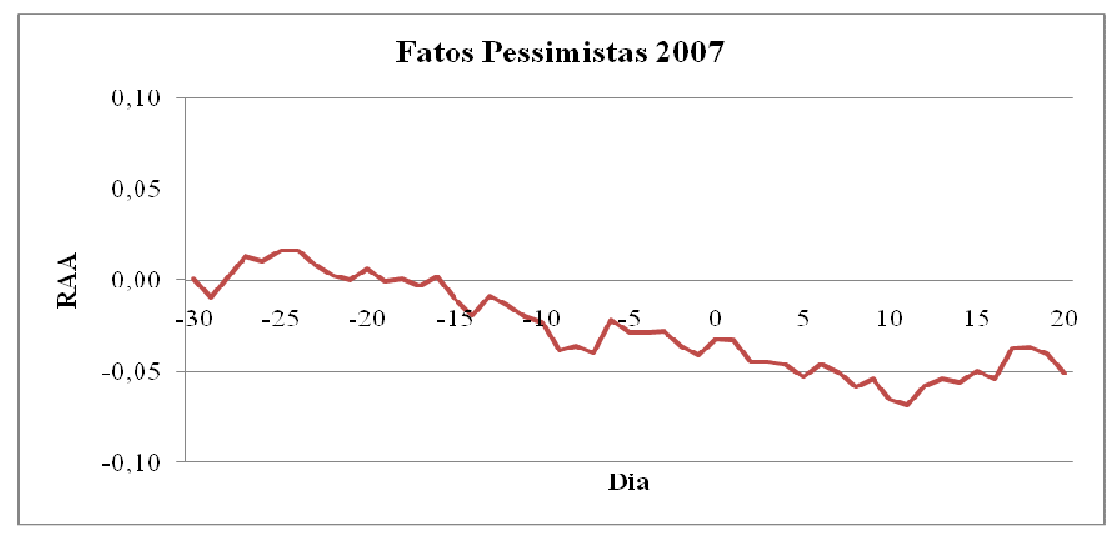

Nota: A data de publicação do fato relevante é representada pelo dia 0 .

De modo geral, o decréscimo no retorno anormal durante a janela de evento. $O$ início do comportamento negativo da variável pode ser identificado acerca de 24 dias antes da publicação do fator relevante, persistindo de forma mais acentuada em torno de 12 dias após a divulgação do fato relevante. O RAA médio no dia -5 é de 0,01629 , chegando a 0,06870 no 11 으. dia. 
Neste caso, o comportamento decrescente da variável pode ser relacionado às notícias divulgadas na data representada graficamente como dia 0 (zero). A reação antecipada do mercado à informação pode ser atribuída à especulação sobre más notícias ou mesmo ao vazamento das informações. Desta forma, percebe-se a influência dos fatos relevantes pessimistas divulgados em 2007 sobre o comportamento de investidores.

O RAA relacionado aos fatos pessimistas de 2006 apresenta queda acentuada durante o período próximo à divulgação do fato relevante, cerca de quatro dias antes e um dia após a publicação, não persistindo por toda a janela de evento. Já, o RAA relacionado aos fatos pessimistas de 2007 apresenta queda menos acentuada, no entanto, persistente por toda a janela de evento.

Embora não se identifiquem divergências significativas entre os fatos relevantes pessimistas publicados em 2006 e 2007, a divergência de comportamento da variável pode ser explicada pela situação das empresas nos períodos em questão. Desta forma, supõe-se que as empresas analisadas em 2007 apresentem situação negativa persistente, capaz de refletir-se nos comunicados da imprensa. Já, as empresas analisadas em 2006 apresentariam, predominantemente, uma situação negativa momentânea ou facilmente superável frente a um histórico positivo.

Com o objetivo de complementar as análises anteriores, optou-se por efetuar o cálculo do RAA considerando apenas os fatos relevantes relacionados a ações com $R_{2}$ superior a 0,5. $\mathrm{O} R_{2}$, neste caso, representa a correlação existente entre o retorno das ações da empresa e o retorno o mercado (Ibovespa) e foi calculado com o auxílio do software Excel, considerando o intervalo entre o décimo quinto e o vigésimo dias anteriores à divulgação de cada fato relevante.

A partir destes novos parâmetros, foram analisados 37 fatos otimistas e 1 pessimista, referentes a 2007, 37 fatos otimistas e 2 pessimistas, divulgados durante o ano de 2006. Os Retornos Anormais Acumulados das ações de comportamentos mais aproximados ao do mercado foram calculados e os resultados obtidos estão representados nas Figuras 5, 6, 7 e 8.

Figura 5: Retorno Anormal Acumulado - Maior Correlação com o Mercado - Fatos Otimistas 2006

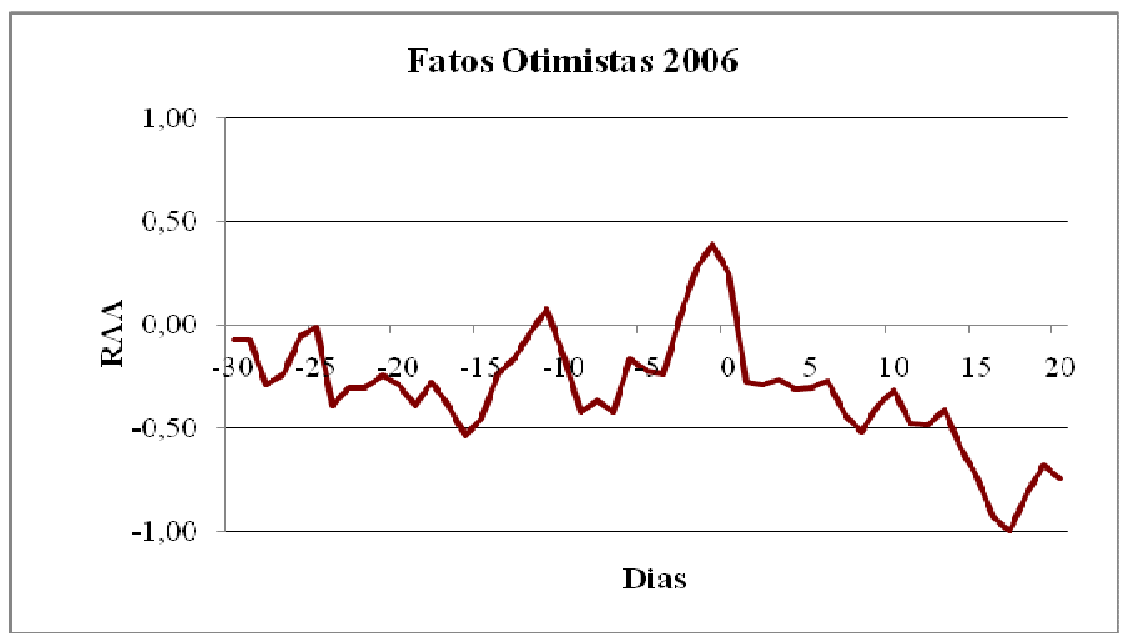

Nota: A data de publicação do fato relevante é representada pelo dia 0. 
Na Figura 5 demonstra-se o comportamento do RAA das ações com forte correlação com o Ibovespa e que apresentaram fatos relevantes divulgados em 2006. É possível perceber que a o RAA atinge seu ponto máximo, 0,39021, no dia anterior à divulgação do fato relevante, apresentando queda acentuada nos dias subseqüentes e chegando a -0,99520 no 170 dia.

Tal comportamento pode ser explicado por um possível vazamento de informações antes da divulgação da comunicação oficial do fato, o que possibilitaria ao mercado uma reação antecipada e pouco duradoura, pois após a publicação do fato, o retorno volta a ter reações que não podem ser associadas ao otimismo dos investidores.

Ao serem comparadas as Figuras 1 e 5, é possível perceber uma maior oscilação no retorno acumulado das ações na última figura, principalmente, se considerada a variação na escala adotada em ambos.

Figura 6: Retorno Anormal Acumulado - Maior Correlação com o Mercado - Fatos Pessimistas 2006

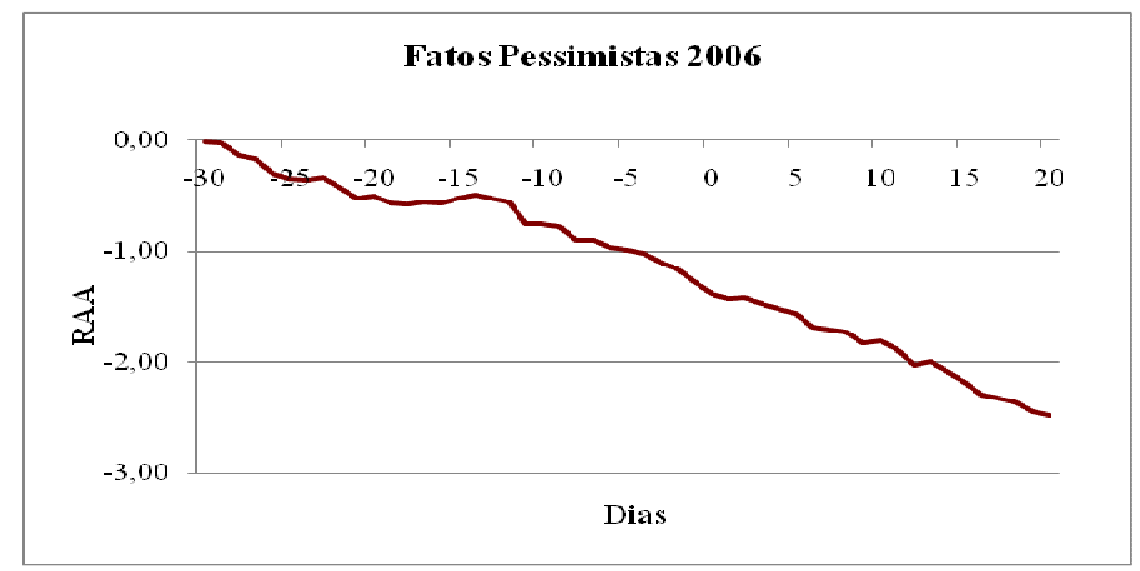

Nota: A data de publicação do fato relevante é representada pelo dia 0.

Na Figura 6 demonstra-se o comportamento do RAA das ações de duas companhias, a Refinaria de Petróleo Ipiranga S. A e a Tim Participações S.A. Diferentemente do resultado representado pela Figura 2, a Figura 6 apresenta a queda do retorno anormal acumulado durante todo o período em estudo, não podendo ser associado à comunicação do fato pessimista. Não é possível associar uma reação do mercado à linguagem utilizada nos comunicados em estudo e, neste caso, tais comunicações podem representar meras constatações de situações desfavoráveis já conhecidas. 
Figura 7: Retorno Anormal Acumulado - maior correlação com o mercado - fatos otimistas 2007

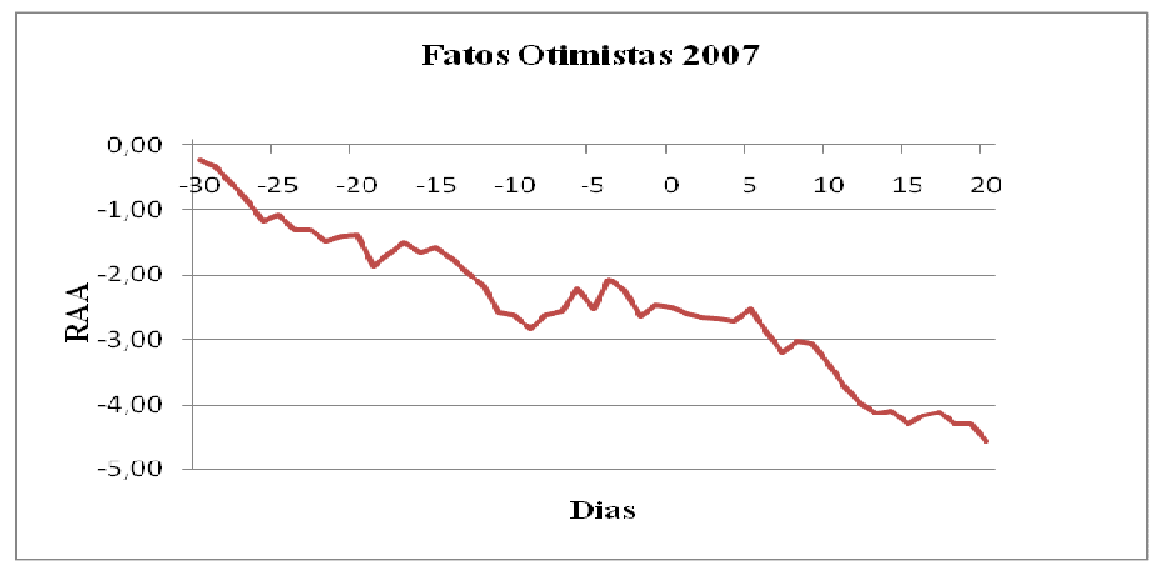

Nota: A data de publicação do fato relevante é representada pelo dia 0.

Observa-se que o RAA dos fatos otimistas de 2007 apresenta queda acentuada durante os 50 dias em estudo, partindo de $-0,24005$ no trigésimo dia anterior à divulgação do fato relevante e chegando a $-4,57751$ no vigésimo dia após sua publicação. O retorno eleva-se de $-2,84725$, no dia -9 , para $-2,7374$, no dia -4 . No entanto, diante das constantes oscilações no retorno anormal durante todo o período, sem, contudo, interromper a queda acentuada do mesmo, não é possível associar esta elevação à publicação do fato relevante na data 0 .

Ao comparar o RAA referente aos fatos otimistas divulgados em 2007 (Figura 3) com o RAA das ações de forte correlação com o mercado (Figura 7), observa-se a diferença no comportamento da variável nos períodos. Enquanto o retorno representado na Figura 3 apresentou variações inexpressíveis, o retorno anormal acumulado na Figura 7 apresenta queda durante o período em análise, apesar da publicação de comunicados considerados otimistas.

Na Figura 8 representa-se a oscilação do retorno anormal médio acumulado das ações da companhia Energias do Brasil S.A., no período anterior e posterior à divulgação de um fato relevante, publicado em 29 de agosto de 2007.

Figura 8: Retorno Anormal Acumulado - Maior Correlação com o Mercado - Fatos Pessimistas 2007

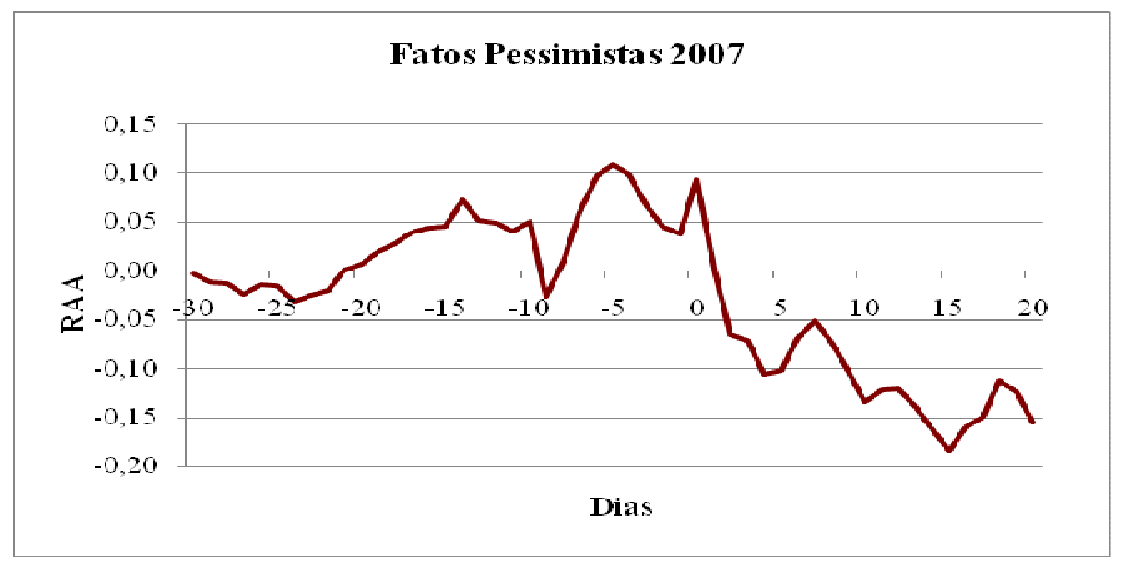


Nota: A data de publicação do fato relevante é representada pelo dia 0.

O comportamento de tal RAA apresenta redução de 0,10775 , no dia -5 , para 0,03694 , no dia -1. Na data da divulgação do fato relevante, o retorno anormal acumulado volta a elevar-se, auferindo o valor de 0,09255, e sofre redução nos dias posteriores, até atingir o valor de -0,10573 no dia 4. Embora ocorram breves elevações durante o período em estudo, observa-se uma redução geral do RAA do dia - 5 ao dia 15 , o que pode ser associado à linguagem pessimista utilizada na divulgação publicada no dia 0 , ou mesmo à situação da companhia no período.

É importante ressaltar a unidade de escala utilizada no eixo y. Nas Figuras 1, 2, 3, 4 e 8, a escala utilizada é bem menor que aquela utilizada nas Figuras 5, 6 e 7, o que demonstra maiores amplitudes nas variações representadas por estes últimos. Ao comparar os resultados de empresas com fatos divulgados de forma pessimista em 2006 e 2007, percebe-se a tendência dos retornos anormais das ações ao decréscimo, enquanto os retornos relacionados aos fatos divulgados positivamente no mesmo período apresentam variações pouco significativas.

Observa-se que o mercado financeiro encara as divulgações otimistas com maior cautela, atendo-se mais às informações prestadas que, propriamente, à linguagem empregada. Já, as divulgações pessimistas são capazes de causar maiores reações em seus usuários, o que pode ser atribuído ao conservadorismo do mercado, que delega maior credibilidade às notícias negativas que às positivas.

Outra explicação é a resistência das empresas à utilização de abordagem negativa em suas comunicações, haja vista o reduzido número de fatos relevantes classificados como pessimistas frente àqueles considerados otimistas. Assim, infere-se que as companhias só optem pela utilização de narrativas pessimistas quando as situações são, inegavelmente, desfavoráveis, enquanto a linguagem otimista não se restrinja às boas notícias.

Mackinlay (1997) sugere a realização de testes não paramétricos, isentos de pressupostos quanto ao conhecimento da distribuição da variável na população, sobre a distribuição dos retornos anormais, para proporcionar a verificação da solidez das conclusões baseadas em ensaios paramétricos.

Visando atender a este objetivo, optou-se por aplicar o teste de Wilcoxon, que é similar ao teste de sinais em essência, mas que considera a magnitude do aumento ou da diminuição da variável e não apenas a direção da variação para mais ou para menos. O teste foi aplicado sobre o retorno anormal médio por ação de cada um dos dias anteriores e posteriores à publicação dos fatos relevante. As distribuições $\overline{R A}_{\bar{T}}$ (3.4) dos vinte dias anteriores à data de ocorrência do evento foram comparadas às dos vinte dias seguintes à data 0 , segregados pela linguagem e ano de publicação dos fatos relevantes a que se referem. Os resultados auferidos foram sintetizados na Tabela 4. 
Tabela 4: Teste de Wilcoxon

\begin{tabular}{|c|c|c|c|c|c|}
\hline & & & $\mathrm{N}$ & $\begin{array}{l}\text { Média das } \\
\text { Classificações }\end{array}$ & $\begin{array}{l}\text { Soma das } \\
\text { Classificações }\end{array}$ \\
\hline \multirow{4}{*}{$\begin{array}{l}\text { VAR00002 } \\
\text { VAR00001 }\end{array}$} & - & Classificações Negativas & 13(a) & 12,08 & 157,00 \\
\hline & & Classificações Positivas & $7(b)$ & 7,57 & 53,00 \\
\hline & & Coincidências & 0 (c) & & \\
\hline & & Total & 20 & & \\
\hline \multirow{4}{*}{$\begin{array}{l}\text { VAR00004 } \\
\text { VAR00003 }\end{array}$} & - & Classificações Negativas & $10(d)$ & 8,80 & 88,00 \\
\hline & & Classificações Positivas & $10(e)$ & 12,20 & 122,00 \\
\hline & & Coincidências & $0(f)$ & & \\
\hline & & Total & 20 & & \\
\hline \multirow{4}{*}{$\begin{array}{l}\text { VAR00006 } \\
\text { VAR00005 }\end{array}$} & - & Classificações Negativas & $12(\mathrm{~g})$ & 11,75 & 141,00 \\
\hline & & Classificações Positivas & $8(h)$ & 8,63 & 69,00 \\
\hline & & Coincidências & $0(i)$ & & \\
\hline & & Total & 20 & & \\
\hline \multirow{4}{*}{$\begin{array}{l}\text { VAR00008 } \\
\text { VAR00007 }\end{array}$} & - & Classificações Negativas & $11(\mathrm{j})$ & 9,36 & 103,00 \\
\hline & & Classificações Positivas & $9(k)$ & 11,89 & 107,00 \\
\hline & & Coincidências & $0(\mathrm{l})$ & & \\
\hline & & Total & 20 & & \\
\hline
\end{tabular}

Notas: a VAR00002 < VAR00001; b VAR00002 > VAR00001; c VAR00002 = VAR00001

d VAR00004 < VAR00003; e VAR00004 > VAR00003; f VAR00004 = VAR00003

g VAR00006 < VAR00005; h VAR00006 > VAR00005; i VAR00006 $=$ VAR00005

j VAR00008 < VAR00007; k VAR00008 > VAR00007; I VAR00008 = VAR00007

Onde:

VAR 00001 = retorno anormal médio por ação anterior à divulgação de fatos relevantes otimistas em 2006

VAR 00002 = retorno anormal médio por ação posterior à divulgação de fatos relevantes otimistas em 2006

VAR 00003 = retorno anormal médio por ação anterior à divulgação de fatos relevantes pessimistas em 2006

VAR 00004 = retorno anormal médio por ação posterior à divulgação de fatos relevantes pessimistas em 2006

VAR 00005 = retorno anormal médio por ação anterior à divulgação de fatos relevantes otimistas em 2007

VAR 00006 = retorno anormal médio por ação posterior à divulgação de fatos relevantes otimistas em 2007

VAR 00007 = retorno anormal médio por ação anterior à divulgação de fatos relevantes pessimistas em 2007

VAR 00008 = retorno anormal médio por ação posterior à divulgação de fatos relevantes pessimistas em 2007

Observa-se que os retornos anormais médios das ações otimistas após a divulgação dos fatos relevantes (VAR 00002 e VAR 00006) apresentaram, de forma geral, valores negativos quando comparados aos mesmos retornos antes das datas dos eventos (VAR 00001 e VAR 00005). Tal resultado demonstra que a publicação dos comunicados na data 0 não foi capaz de influenciar positivamente o investidor, como imaginado inicialmente, uma vez que o retorno anormal das ações não sofreu incremento nos dias posteriores à data do evento.

Os retornos referentes aos fatos pessimistas apresentaram, em 2006, a mesma proporção de sinais positivos e negativos antes e depois da divulgação dos fatos relevantes, enquanto, em 2007, os retornos após o evento apresentaram mais sinais negativos que aqueles computados antes da data zero. Tais dados demonstram alguma influência exercida pelos fatos relevantes pessimistas no preço das ações em 2007.

Na Tabela 5 apresenta-se ainda o número médio de classificações positivas e negativas e a soma destas classificações. Observa-se que ao comparar fatos otimistas (VAR00002 VAR00001 e VAR00006 - VAR00005), tanto o número médio quanto a soma de 
classificações negativas foram superiores às positivas. $O$ inverso ocorreu com os fatos pessimistas (VAR00004 - VAR00003 e VAR00008 - VAR00007), onde as classificações positivas destacaram-se em relação às negativas.

Tabela 5: Estatística - Teste de Wilcoxon

\begin{tabular}{|c|c|c|c|c|}
\hline & $\begin{array}{l}\text { VAR00002 } \\
\text { VAR00001 } \\
\end{array}$ & $\begin{array}{l}\text { VAR00004 } \\
\text { VAR00003 } \\
\end{array}$ & $\begin{array}{l}\text { VAR000006 } \\
\text { VAR000055 }\end{array}$ & $\begin{array}{l}\text { VAR00008 } \\
\text { VAR00007 } \\
\end{array}$ \\
\hline Z & $-1,941(a)$ &,$- 635(b)$ & $-1,344(a)$ &,$- 075(b)$ \\
\hline$P$ & 052, & ,526 & 179, & 940, \\
\hline
\end{tabular}

Nota: a Baseado em classificações positivas; b Baseado em classificações negativas;

c Teste de Sinais de Classificações.

Nota-se que o teste estatístico, cálculo do escore z e significância $p$, dos fatos otimistas é baseado em classificações positivas e dos fatos pessimistas em classificações negativas. Observa-se, ainda, que na análise dos quatro casos representados na tabela 5 as significâncias apresentam valores superiores a $5 \%(p>0,05)$ o que demonstra a baixa influência dos eventos no comportamento das variáveis.

Assim, os fatos otimistas de 2006 e 2007 apresentam escores z de -1.941 e -1.344 e estes valores são significantes quando $p=0,052$ e $p=0,179$, respectivamente, o que representa o declínio dos retornos anormais médios das ações após a divulgação de eventos otimistas. De forma análoga, os fatos pessimistas de 2006 e 2007 apresentam escores z de $-0,635$ e $-0,075$ quando $p=0,536$ e 0,940, respectivamente. Diante de tais valores, pode-se afirmar que o retorno anormal das ações apresentou elevação após a divulgação de fatos pessimistas.

\section{CONSIDERAÇÕES FINAIS}

A CVM determina que as companhias abertas divulguem, de forma ampla, toda informação capaz de influir nas decisões de seus acionistas e investidores. No entanto, não há monitoramento, auditoria ou delimitação da estrutura destes comunicados, o que permite às companhias escolher livremente a linguagem a ser empregada nas divulgações a seus usuários.

$\mathrm{Na}$ tentativa de responder a pergunta inicial - seria a linguagem utilizada para a divulgação de fatos relevantes capaz de interferir no valor de ações em negociação? - as conclusões obtidas com o estudo podem ser segregadas de acordo com a linguagem dos fatos relevantes.

A linguagem otimista não apresentou influência significativa nos preços das ações, ou seja, o preço das ações das companhias não se elevou de forma relevante durante o intervalo da janela de evento, contrariando a suposição que previa o contrário. A linguagem pessimista apresentou certa influência sobre a variação dos retornos anormais das ações, uma vez que estes últimos tenderam ao decréscimo durante o período em análise. No entanto, as variáveis não se comportaram de modo uniforme durante os dois anos 
analisados, o que deixa claro que não pode ser atribuído unicamente à reação à linguagem dos comunicados o comportamento do mercado financeiro.

Uma das possíveis explicações para o resultado auferido é a desconsideração da linguagem dos comunicados por seus destinatários. Estes estariam preparados para interpretar a mensagem sem se deixar influenciar pelo modo como esta é transmitida. Assim, o decréscimo no retorno anormal acumulado das ações relacionadas a fatos pessimistas pode ser explicado pelo anúncio efetivo de más notícias, ou seja, as empresas só optam por utilizar uma linguagem pessimista nos casos em que esta é inevitável.

A partir dos resultados e conclusões obtidos espera-se contribuir com o aprimoramento e eventuais reformulações na divulgação não só de fatos relevantes, como também, de informações contábeis de uma forma geral.

Sugere-se, ainda, que novas pesquisas sejam conduzidas para avaliar outros fatores ligados à evidenciação que possam influir na variação dos retornos das ações das companhias, além de outros estudos relacionados às peculiares características dos fatos relevantes e das circunstâncias que os geram.

\section{REFERÊNCIAS}

BALL, R.; BROWN, P. An Empirical Evaluation of Accounting Income Numbers. Journal of Accounting Research, v. 6, p. 159-178, Autumn, 1968.

BEAVER, W. Market Prices, Financial Ratios, and the Prediction of Failure. Journal of Accounting Research, p. 179-192, Autumn, 1968.

BOLSA DE VALORES DE SÃO PAULO - BOVESPA. Índice Bovespa - Ibovespa. Disponível em: $<$ http://www.bovespa.com.br/Mercado/RendaVariavel/Indices/FormConsultaApresentacaoP.as p ?indice=lbovespa $>$. Acesso em: 13 de agosto de 2008.

BRASIL. Lei das sociedades por ações. Lei 6.404, de 15 de Dezembro de 1976. Publicado no Diário Oficial da União em 17.12.77. Disponível em: <www.planalto.gov.br>. Acesso em: 09 de fevereiro de 2007.

BROOKS, C. Introductory econometric for finance. New York, N.Y.: Cambridge University Press, 2005.

COMISSÃO DE VALORES MOBILIÁRIOS - CVM. Cadernos CVM. A divulgação de Informações. Disponível em: <http://www.cvm.gov.br/port/protinv/caderno8.asp>. Acesso em: 01 de junho de 2008.

COMISSÃO DE VALORES MOBILIÁRIOS - CVM. Instrução CVM n 358, de 3 de janeiro de 2002. Disponível em: <http://www.cvm.gov.br>. Acesso em: 28 de maio de 2007.

COURTIS, J. Annual report readability variability: tests of the obfuscation hypothesis. Accounting, Auditing \& Accountability Journal, v. 11, n. 4, p. 459-471, 1998.

DIAS FILHO, J. M. A linguagem utilizada na evidenciação contábil: uma análise de sua compreensibilidade à luz da Teoria da Comunicação. Caderno de Estudos, v. 13, n. 24, p. 38-49, São Paulo: FIPECAFI, 2000. 
; NAKAGAWA, M. Análise do processo da comunicação contábil: uma contribuição para a solução de problemas semânticos, utilizando conceitos da teoria da comunicação. Revista Contabilidade \& Finanças, v. 15, n. 26, p. 42-57, 2001.

GOOGLE. Google Acadêmico. Disponível em: <http://scholar.google.com>. Acesso em: 01 de setembro de 2008.

LAMOUNIER, W. M.; NOGUEIRA, E. M. Estudo de Eventos: procedimentos e estudos empíricos. Disponível em:

http://www.fae.edu/publicacoes/pdf/Ilseminario/iniciacaoCient\%C3\%ADfica/iniciacao_01.pdf>. Acesso em: 10 de agosto de 2007.

LOPES, A. B.; LOSS, L.; SARLO NETO, A.; TEIXEIRA, A. J. C. O Diferencial no Impacto dos Resultados Contábeis nas Ações Ordinárias e Preferenciais no Mercado Brasileiro. Revista Contabilidade e Finanças, São Paulo, n. 37, p. 46 - 58, jan./abr. 2005

MACKINLAY, A. Event sudies in economic and finance. Journal of Economic Literature, v.35, p. 1339, 1997.

PEREIRA, C. C. Efeito das Notícias Pré-Divulgadas no Lucro: uma análise no setor de metalurgia e siderurgia brasileira. Brasília, 2006. 91 p. Dissertação (Mestrado em Ciências Contábeis) Programa Multiinstitucional e Inter-Regional de Pós-Graduação em Ciências Contábeis (UnB, UFPB, UFPE, UFRN).

PEREIRA, V. A. dos S. A imprensa como veículo de divulgação dos Fatos Relevantes: um estudo empírico sobre a variação temporal na divulgação dessas notícias pela imprensa. Trabalho de Conclusão de curso (Artigo - Graduação) - Universidade de Brasília, 1잉.

RODRIGUES, Fernanda F. Análise das Variáveis que Influenciam as Informações Divulgadas nos Relatórios da Administração das Companhias Abertas Brasileiras: um estudo empírico nos anos de 2001 a 2003. Brasília, 2005. Dissertação de Mestrado - Programa Multiinstitucional e InterRegional de Pós-Graduação em Ciências Contábeis (UnB, UFPB, UFPE, UFRN) - Universidade de Brasília.

SILVA, C. A. T.; FERNANDES, J. L. T. Análise da Legibilidade dos Textos Narrativos dos Fatos Relevantes Divulgados pelas Empresas Brasileiras de Capital Aberto nos Anos de 2002 a 2006. In: CONGRESSO USP DE INICIAÇÃO CIENTÍFICA. 4, 2007, São Paulo, Anais... São Paulo: EAC/FEA/USP, 2007.

VERRECCHIA, R. E. Essays on disclosure. Journal of Accounting and Economics, n. 32, p. 97-180, 2001. 